\title{
A PROCESS-BASED MODEL OF SNOW DRIFTING
}

\author{
by
}

\author{
J.W. Pomeroy*
}

(School of Environmental Sciences, University of East Anglia, Norwich NR4 7TJ, England, U.K.)

\section{ABSTRACT}

This physics-based two-phase flow model of the mass balance of drifting snow calculates the transport of snow through saltation and suspension, and recognizes the important role of in-transit sublimation on surface-erosion rates. Measurements of the vertical gradient of drifting snow-mass flux and wind speed in the surface-boundary layer indicate the total flux of saltating snow increases linearly with wind speed and is sensitive to the transport threshold. The total flux of suspended snow requires saltation to become established, and increases with the cube of both the total flux of saltating snow and the wind speed. The total suspended flux quickly becomes the dominant transport mode as wind speeds increase beyond threshold levels, and comprises more than $90 \%$ of the total flux for wind speeds greater than $15 \mathrm{~m} \mathrm{~s}^{-1}$. Sublimation rates estimated from wind speed, temperature, and humidity are sufficiently balanced by snow-surface erosion rates to ablate completely snow-packs with depths of the order $200 \mathrm{~mm}$, a typical value for steppe and prairie environments.

\section{INTRODUCTION}

Divergent lines of thought have developed amongst scientists and engineers regarding methods for estimating the quantity of wind-blown snow transported, deposited, and eroded over the Earth's surface. Some workers have emphasized saltation of snow as the dominant mass-transport process (Dyunin and Kotlyakov, 1980; Takeuchi, 1980; Schmidt, 1986); others have shown that significant quantities of snow are carried in suspension by upper-level drifting (Mellor and Radok, 1960; Budd and others, 1966). Tabler (1975) calculated transport of snow using a seasonal mass balance, whilst Pomeroy and Male (1986) applied an hourly massbalance to calculate erosion and transport over agricultural landscapes.

The process-based model described in this paper has been derived from two-phase flow principles and from measurements of drifting snow, so as to assist in reconciling the variant approaches and in order to provide an analytical framework which suggests necessary research and provides a practical tool for snow-management designs. The processes pertinent to the model are saltation, suspension, and sublimation. They are addressed separately, and their importance for mass transport and surface erosion of snow is noted.

\section{MEASUREMENTS}

During January and February 1987, drifting-snow flux and related atmospheric parameters were measured on a completely snow-covered and treeless plain, located $4 \mathrm{~km}$ west of the limits of the City of Saskatoon, Canada. Snow

\footnotetext{
* Present address: Rocky Mountain Forest and Range Experiment Station, U.S. Forest Service, 222 South 22nd Street, Laramie, WY 82070-5299, U.S.A.
}

cover between 100 and $180 \mathrm{~mm}$ deep and ranging from 5 to $760 \mathrm{kN} \mathrm{m}^{-2}$ in surface hardness provided an undisturbed up-wind fetch of $500 \mathrm{~m}$. Wind speeds at $10 \mathrm{~m}$ height during measurement events varied from 5 to $15 \mathrm{~m} \mathrm{~s}^{-1}$, and air temperatures ranged from $-17^{\circ}$ to $+1{ }^{\circ} \mathrm{C}$. Wind speeds at the threshold of snow transport varied from 5 to $9 \mathrm{~m} \mathrm{~s}^{-1}$.

Wind speeds and air temperatures were measured in a vertical transect above the surface to a height of $3 \mathrm{~m}$. The mass flux of drifting snow was measured with opto-electronic particle detectors (Brown and Pomeroy, in press), one set in saltation, approximately $10 \mathrm{~mm}$ above the surface, and the others spaced logarithmically in a vertical transect to a height of $2 \mathrm{~m}$. Each recorded observation is an average of measurements taken over a period of $7.5 \mathrm{~min}$.

\section{MODEL}

This section briefly outlines mathematical descriptions for saltation, suspension, sublimation, and erosion, developed from both two-phase flow theory and measured data. For a more detailed discussion of the development, the reader is referred to Pomeroy (unpublished).

\section{Saltation}

Saltation refers to the horizontal transport of particles in curved trajectories, which are near to and periodically impact on, the surface. Saltation trajectories for snow are rarely more than a few millimetres in height. Bagnold (1941) related saltating flow of sand to the kinetic energy available to support the flow, Dyunin (1954) applied Bagnold's ideas to drifting snow, and these concepts are here used to develop an expression for the total mass flux of saltating snow.

The total mass flux of saltating snow, $Q_{\text {salt }}$ is the mean saltating mass moving at some mean velocity, $u_{\mathrm{p}}$, where

$$
Q_{\text {salt }}=u_{\mathrm{p}} \frac{W_{\mathrm{p}}}{g}
$$

$W_{\mathrm{p}}$ is the mean weight of snow saltating over a surface, $g$ is the gravitational acceleration constant. Proceeding from reasoning expounded by Owen (1964), and applied by Schmidt (1986) to drifting snow, the weight of saltating snow is assumed to be related to the magnitude of the flow-shear stress which is experienced by the particles. Subtracting the shear stress applied to non-erodable surface elements, $\tau_{n}$, and the shear stress applied to the erodable surface, $\tau_{l}$, from the total atmospheric shear stress, $\tau$, yields the expression

$$
W_{\mathrm{p}}=e\left(\tau-\tau_{n}-\tau_{t}\right)
$$

The coefficient, $e$, is the efficiency of saltation and is inversely related to the friction resulting from particle impact and ejection at the snow surface, as the horizontal shear stress applied to the particles is transformed into a normal force which supports the weight of the particles. The saltation efficiency ranges from 0 to 1 , where $e=0$ for complete loss of particle momentum after surface impact, and $e=1$ for no friction losses. 


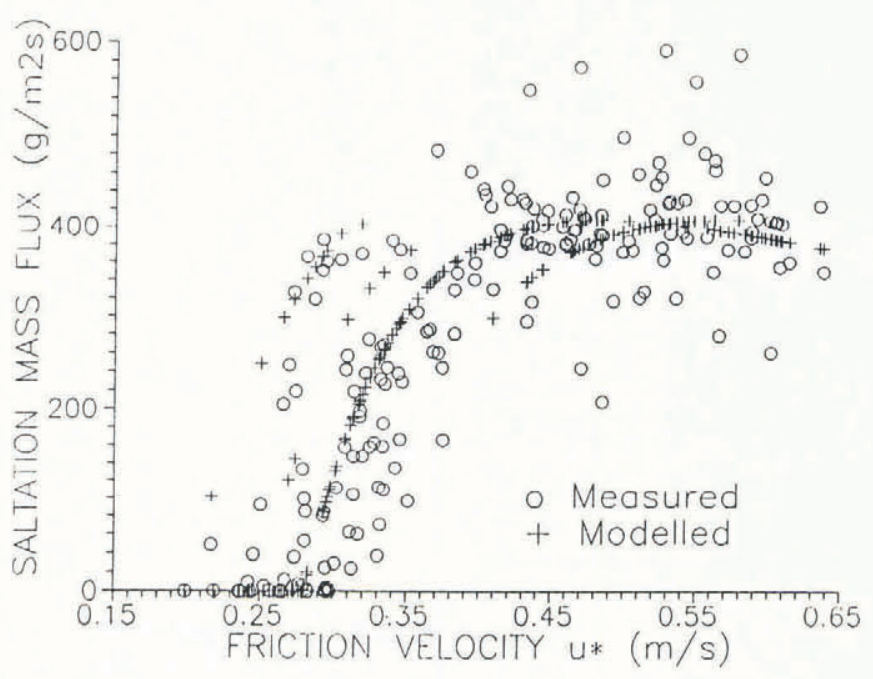

Fig. 1. Measured and modelled (197 values each) saltating mass flux of snow per unit area perpendicular to flow, plotted with atmospheric friction velocities.

Field observations and empirical relationships provide a basis for evaluation of $u_{\mathrm{p}}, e, \tau, \tau_{n}$, and $\tau_{t}$ in Equations (1) and (2); the mean wind speed in the saltation layer is assumed to be proportional to the saltation velocity, $u_{\mathrm{p}}$. Above the saltation layer, the vertical gradient of wind speed in drifting snow is described by a logarithmic slope, $u^{*}$, the friction velocity, and zero wind-speed intercept, $z_{0}$, the aerodynamic roughness height. Bagnold (1941) reported that, for any upper-level wind speed, vertical gradients of wind speed converge at a constant wind-speed focus within the layer of saltating sand, the wind speed at and beneath this focus height being nearly constant at the value sustained for the transport threshold. Pomeroy (unpublished) showed that the height of the Bagnold focus is positively related to wind speed and also to aerodynamic roughness height during drifting, and to the wind speed and aerodynamic roughness height at the transport threshold.

The focus heights calculated using friction velocities, aerodynamic roughness heights, and transport thresholds measured in this experiment are all greater than $10 \mathrm{~mm}$, except for near-threshold friction velocities. For example, given $u^{*}=0.5 \mathrm{~m} \mathrm{~s}^{-1}$, threshold friction velocity $u^{*}{ }_{t}=$ $0.2 \mathrm{~m} \mathrm{~s}^{-1}, z_{0}=1.5 \mathrm{~mm}$, and threshold aerodynamic roughness height $z_{0}=0.2 \mathrm{~mm}$, the focus height is $20 \mathrm{~mm}$. Note that roughness heights measured here are approximately an order of magnitude greater than those measured by Bagnold (1941) for drifting sand, and by Tabler (1980) for drifting snow over a snow-covered lake. The height of the wind-speed focus is of the order of the assumed height of the saltating particle trajectories, so that the wind speed at the focus height dominates wind speeds within the layer of saltating particles. Because, in the saltation layer, saltation velocity is proportional to wind speed and also to threshold wind speed and, since threshold wind speeds are proportional to the threshold friction velocity, it follows that saltation velocity, $u_{\mathrm{p}}$, is proportional to threshold friction velocity.

Measured values of the mass flux of saltating snow through a differential area normal to the flow suggest a value for the saltation velocity proportionality constant and a function for the saltation efficiency, $e$. Assuming $e$ attains its maximum value of 1.0 within the range of measurements taken, the ratio of saltation velocity to threshold friction velocity is $2.3: 1$. Measured mass fluxes suggest that the saltation efficiency is inversely proportional to the friction velocity; hence $e=1 / 3.25 u^{*}$.

An atmospheric shear stress is found from a friction velocity, $u^{*}$, noting that $\tau_{x}=u_{x}^{* 2} \rho$ where $\rho$ is the flow density. Hence, $\tau_{n}$ is determined using semi-empirical drag-partition techniques which have been outlined by Lyles and Allison (1976) and Tabler and Schmidt (1986). In 1964, Owen proposed that surface-shear stress, $\tau_{t}$, equals total shear stress at the threshold of transport, which is also the kinetic energy level at which particle movement ceases.

Combining the results of measurements and theory leads to the following expression for total mass flux of saltating snow

$$
Q_{\text {salt }}=\frac{0.71 \rho_{\mathrm{a}}}{u^{*} g}\left[u^{*}{ }^{*} u^{* 2}-u^{*}{ }_{t} u_{n}^{* 2}-u_{t}^{* 3}\right] .
$$

The dimensionless coefficient, 0.71 , combines saltation velocity and efficiency coefficients. For given conditions of non-erodable roughness and threshold, $\mathrm{Q}_{\mathrm{salt}}$ is approximately proportional to friction velocity. Measured and modelled values of saltating mass flux (Fig. 1) show a similar increase with friction velocity. A regression between 197 measured and modelled values of saltating mass flux indicates a coefficient of determination, $R^{2}=0.79$, a standard error of estimate of $73.5 \mathrm{~g} \mathrm{~m}^{-2} \mathrm{~s}^{-1}$, and a mean ratio of predicted-to-measured values of $0.98: 1$.

\section{Suspension}

Suspended drift refers to snow prevented by turbulent eddies in the atmosphere from contacting the surface. Drift density, the atmospheric concentration of suspended snow, decreases dramatically with height but can extend in height for several hundred metres even without snowfall. Theoretical considerations suggest that saltating snow, rather than surface snow, is the source of suspended particles (Anderson, 1987; Pomeroy, unpublished).

The total mass flux of suspended drifting snow, $Q_{\text {susp }}$, is found using the variation of drift density with height, where the drift density is referenced to a constant value at the saltation layer interface. Hence

$$
Q_{\text {susp }}=\frac{u^{*}}{k} \int_{\mathrm{z}_{h}}^{z_{b}} \eta_{z} \ln \left(z / z_{0}\right) \mathrm{d} z
$$

where $\eta_{z}$ is the drift density of snow at height $z ; z_{h}$ is the height at top of saltation layer; $\mathrm{z}_{b}=$ height at top of the boundary layer. In order to solve Equation (4), the distribution of $n_{z}$ with height must be known. Because the mean movement of particles in a turbulent atmosphere can be modelled in an analogy to laminar diffusion, the diffusion equation has been applied by Mellor and Radok (1960), Budd and others (1966), and Schmidt (1982) to describe the vertical distribution of suspended drifting snow. A one-dimensional diffusion equation, based upon mass continuity for sublimating particles undergoing gravitational settling in a turbulent atmosphere can be obtained from

$$
\partial \eta / \partial t=-\partial\left(w n-k_{s_{z}} \partial \eta / \partial z\right) / \partial z-V_{s} \eta
$$

where $w$ is the mean vertical snow-particle velocity; $\boldsymbol{k}_{s}$ is the turbulent diffusivity of drifting snow at height $z ; V_{\mathrm{S}}$ is a rate coefficient accounting for sublimation of snow particles; and $t$ is time. Equation (5) is integrated, given steady-state conditions $(\partial n / \partial t=0)$, to provide

$$
n_{\mathrm{I}}=\eta_{\mathrm{i}}\left(z_{\mathrm{I}} / z_{\mathrm{i}}\right)^{w^{*}} \text {. }
$$

An iterative calculation determines the drift-density profile as follows: from a known reference $n_{\mathrm{i}}=n_{r}$ at $z_{\mathrm{i}}=z_{\mathrm{r}}$, a drift density $\eta_{\mathrm{I}}$ at height $z_{\mathrm{I}}$ is calculated using Equation (6). Calculated values corresponding to position are substituted into parameters specified for position $i$, and $n_{\mathrm{I}}$ is recalculated for a new $z_{\mathrm{I}}$. The interval between $z_{\mathrm{I}}$ and $z_{i}$ must be small, and specification of $w^{*}, n_{r}$, and $z_{r}$ is necessary to perform the iteration.

The diffusion equation requires a lower boundary flux, $E$, the surface erosion rate, to define $w^{*}$ such that

$$
w^{*}=\frac{\left[\left(E+V_{s} m_{r \rightarrow z}\right) / \eta-\langle\omega\rangle\right]}{k u^{*}}
$$

where $m_{r \rightarrow z}$ is the mass of drifting snow between heights $r$ and $z$; and $\langle\omega\rangle$ is the mean terminal fall velocity of drifting snow particles. Drift densities from 324 observations under a wide variety of precipitation conditions and with air temperatures ranging from $-17^{\circ}$ to $+1{ }^{\circ} \mathrm{C}$ provide the empirical approximation 


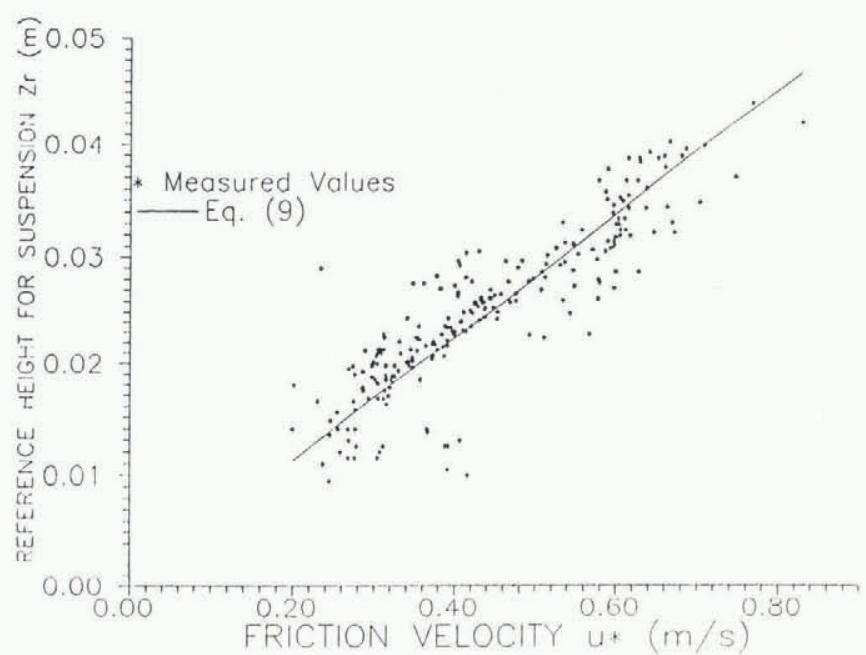

Fig. 2. Height above surface of reference drift density $\left(0.8 \mathrm{~kg} \mathrm{~m}^{-3}\right)$ for suspension of drifting snow (225 values), plotted with atmospheric friction velocities.

$$
w^{*}=-0.8412 z^{-0.544}
$$

The coefficient of determination, $R^{2}=0.82$ for Equation (8), suggests that the right-hand side of Equation (7) is not sensitive to variation in sublimation rate, snowfall, and surface condition.

Measured values of drift density are extrapolated using Equation (6) to a reference value $\eta_{r}=0.8 \mathrm{~kg} \mathrm{~m}^{-3}$ (a value commonly measured at the top of the saltation layer) to determine the height of this reference drift density. Figure 2 shows the reference heights and corresponding friction velocities for a variety of environmental conditions. Assuming a linear relationship, the 225 profiles of drift density indicate

$$
z_{r}=0.05628 u^{*}
$$

with a coefficient of determination $R^{2}=0.76$, and a standard error of estimate $=3.6 \mathrm{~mm}$.

To model suspended drift densities using wind-speed measurements the height, $z_{r}$ of the reference drift density of $0.8 \mathrm{~kg} \mathrm{~m}^{-3}$ is calculated using Equation (9), and drift densities calculated by iteration of Equations (6) and (8) from $z_{h}$ to $z_{b}$. Figure 3 shows modelled drift densities plotted against measured values for both snowfall and non-snowfall conditions, and a variety of wind speeds, snow cover, and air temperatures. The coefficient of determination is $R^{2}=0.84$, and the standard error of estimate is $1.6 \mathrm{~g} \mathrm{~m}^{-3}$ for the total of 761 points. The suspension equations indicate that the total suspended mass flux increases approximately with the fourth power of friction velocity.

\section{Sublimation}

The drifting snow sublimation calculation used in this model is based upon the energy-balance equation of Schmidt (1972), with modifications for turbulence by Lee (unpublished), and for atmospheric gradients of water vapour and sublimation from saltating particles by Pomeroy (unpublished). The controlling factors for sublimation are particle size, wind speed, air temperature, and relative humidity.

\section{Erosion}

Considering the mass balance from a control volume of drifting snow over a unit area of surface yields an estimate of the erosion rate at the surface expressed as

$$
E=Q_{\text {out }}-Q_{\text {in }}+\left[\int_{0}^{z} b\right.
$$

where $E$ is the rate of snow-pack erosion; $Q_{\text {out }}$ and $Q_{\text {in }}$ are the total horizontal mass fluxes of snow leaving and entering the control volume; $\mathrm{d} n_{z} / \mathrm{d} t$ is the sublimation rate

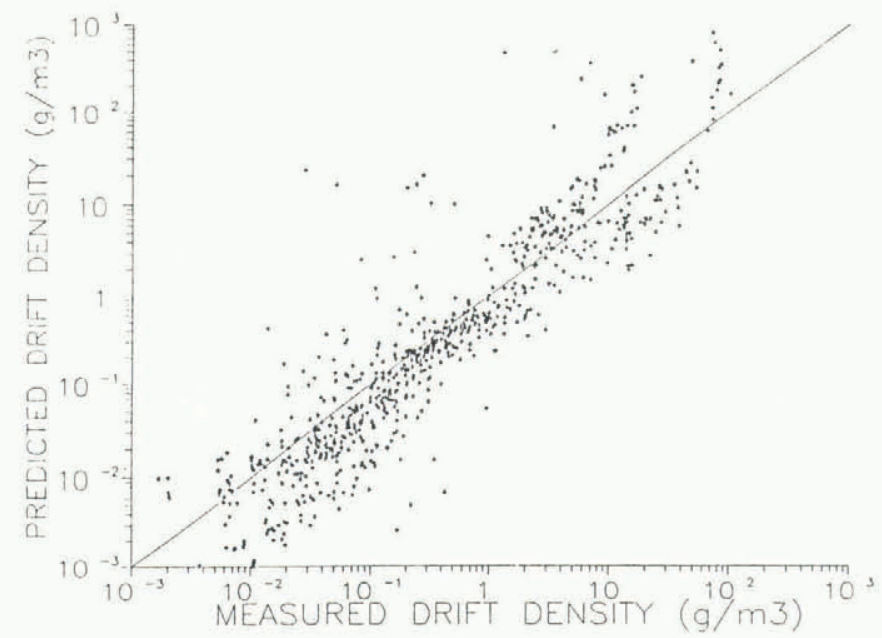

Fig. 3. Modelled drift densities of suspended drifting snow plotted with 761 corresponding measured values.

of drifting snow; and $S$ is the snowfall rate at height $z_{b}$, the top of the boundary layer. The measurements of Takeuchi (1980) and boundary-layer development theory (Hunt and Weber, 1979) suggest fully developed transport, achieved when $Q_{\text {out }}=Q_{\text {in }}$, exists to a height of at least $5 \mathrm{~m}$ for horizontal fetches greater than $400-500 \mathrm{~m}$. In such cases, common to many wind-swept areas, the surfaceerosion rate is controlled by sublimation and snowfall.

\section{RESULTS}

The model detailed above has been compiled in a computer algorithm termed the Prairie Blowing Snow Model (PBSM). Pomeroy (unpublished) provided a full description and listing of the PBSM. Inputs required are wind speed measured at a height of $10 \mathrm{~m}, 10 \mathrm{~m}$ wind speed at the transport threshold, air temperature and relative humidity at a height of $2 \mathrm{~m}$, landscape vegetation geometry, and horizontal fetch. The atmospheric measurements follow the World Meteorological Organization format. For drifting conditions, in which the threshold is not known, $5 \mathrm{~m} \mathrm{~s}^{-1}$ may be assumed. The model accounts for variable fetches in calculating the height of the boundary layer.

Assuming a $500 \mathrm{~m}$ snow-covered fetch, Figure 4 compares the PBSM total mass flux of drifting snow, including saltation and suspension up to a height of $5 \mathrm{~m}$, with the total mass flux of saltating snow only. Saltation comprises less than $10 \%$ of total mass flux for wind speeds greater than $15 \mathrm{~m} \mathrm{~s}^{-1}$; for high wind speeds, the total flux is not sensitive to threshold wind speed. Values of total mass flux calculated using other models are plotted in the same figure. The PBSM fluxes agree well with those predicted by Schmidt (1986). PBSM sublimation rates, for example, are calculated for columns of drifting snow found for fetches of $500 \mathrm{~m}$ over snow-covered uniform terrain. The sublimation rate, plotted as a function of wind speed (Fig. 5), changes over more than an order of magnitude as atmospheric conditions vary over their normal continenta cold-season range. For fully developed flow conditions, erosion rates matching sublimation rates of $25 \mathrm{~mm}$ snow water equivalent per hour can occur in a severe winter storm at temperatures near the melting point of the snow.

\section{CONCLUSIONS}

The model provides a tool which can be used to estimate quantities of drifting snow on an operational basis For instance, the quantities of snow transported across an airport runway may be calculated on an hourly basis using meteorological station measurements. The model also calls attention to the processes which are important for the behaviour of drifting snow. The total flux of saltating snow 


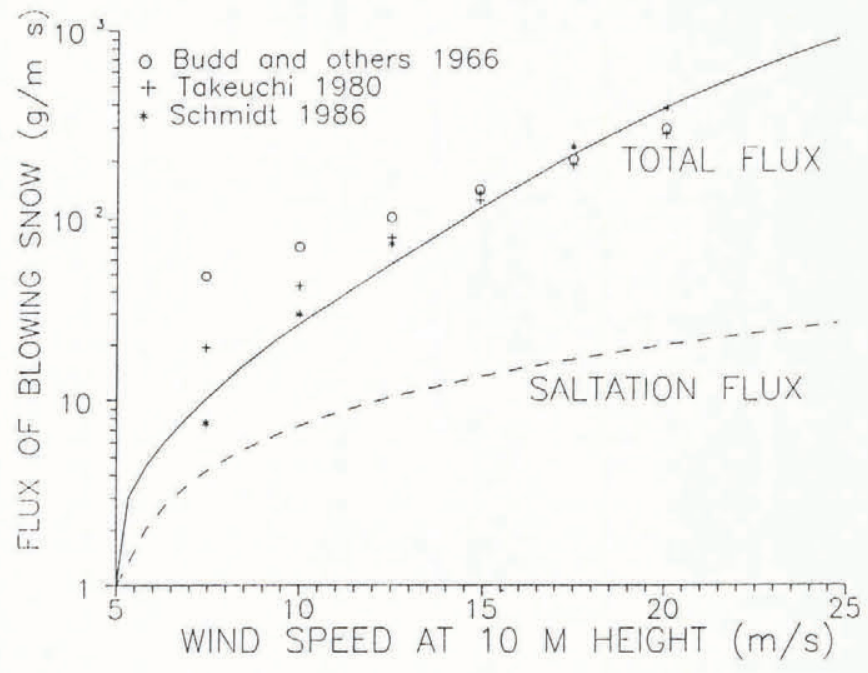

Fig. 4. Prairie Blowing Snow Model horizontal mass flux and saltating mass flux for threshold wind speed of $5 \mathrm{~m} \mathrm{~s}^{-1}$, plotted with $10 \mathrm{~m}$ wind speeds. The data of Budd and others (1966), Takeuchi (1980) for old hardened snow, and Schmidt (1986) for $u_{t}^{*}=0.2 \mathrm{~m} \mathrm{~s}^{-1}$ are plotted for comparison.

is sensitive to threshold conditions, and increases in proportion to wind speed. Because of very rough flow conditions and concomitant low flow velocities, saltation is a notable constituent of total drifting snow flux only for wind speeds below $15 \mathrm{~m} \mathrm{~s}^{-1}$. The total suspended flux of drifting snow is insensitive to threshold conditions, temperature, and snowfall, but requires saltation to become established. It then increases with the cube of wind speed and becomes the dominant mode of transport.

Rates of sublimation from drifting snow vary considerably with wind speed, temperature, and humidity. For non-precipitation conditions in locations with large fetches, surface snow-erosion rate balances drifting snow sublimation rate and is sufficient to ablate completely the shallow snow-packs of the northern prairies of North America.

Because the model calculations are sensitive to mean flow velocities near the surface, to the transition of particles from saltating to suspended motion, and to the height of the two-phase boundary layer, research on these subjects is recommended. Broadly based research on the non-steady-state operation of drifting-snow processes is desirable to permit extension of the model to complex terrain.

\section{ACKNOWLEDGEMENTS}

This research was carried out at the Division of Hydrology, University of Saskatchewan, Saskatoon, Canada. Assistance from Drs D.M. Gray and D.H. Male, T. Brown, and other members of the Division, and support from the Natural Sciences and Engineering Research Council of Canada and the Saskatchewan Research Council are noted. Helpful comments regarding the manuscript were provided by $\operatorname{Dr}$ R.A. Schmidt, Rocky Mountain Forest and Range Experiment Station, Fort Collins, Colorado, U.S.A.

\section{REFERENCES}

Bagnold, R.A. 1941. The physics of blown sand and desert dunes. London, Methuen.

Brown, T. and J.W. Pomeroy. In press. A blowing snow detection gauge. Cold Reg. Sci. Technol.

Budd, W.F., W.R.J. Dingle, and U. Radok. 1966. The Byrd snow drift project: outline and basic results. In Rubin, M.J., ed. Studies in Antarctic meteorology. Washington, DC, American Geophysical Union, 71-134. (Antarctic Research Series 9.)

Dyunin, A.K. 1954. Tverdgy raskhod snegovetrovogo potoka [Solid flux of snow-bearing air flow]. Tr. TransportnoEnergicheskogo Inst., 4, 71-88. [English translation:

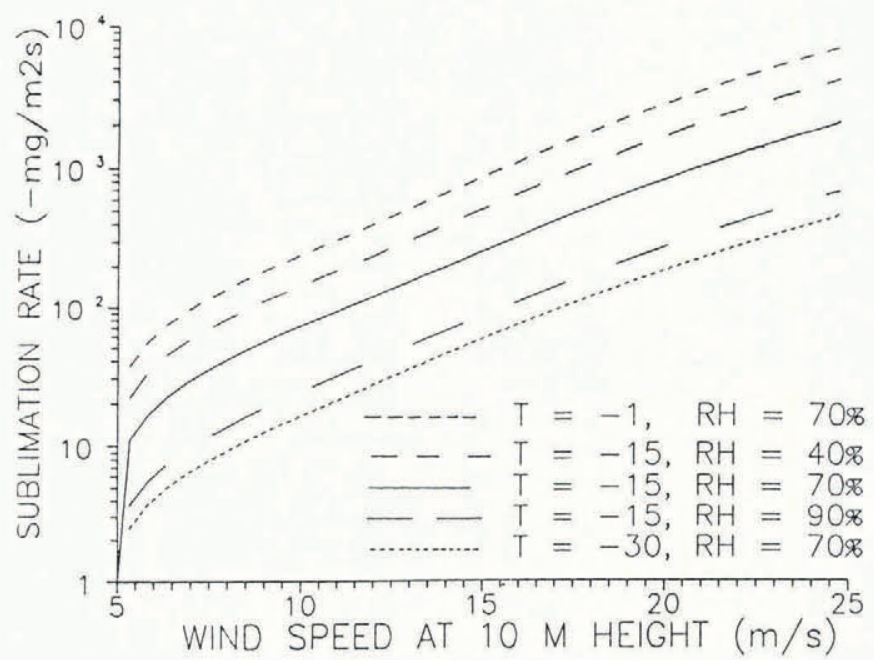

Fig. 5. Prairie Blowing Snow Model sublimation rates within a fully developed column of drifting snow shown for various temperatures and humidities (plotted with $10 \mathrm{~m}$ wind speeds).

National Research Council of Canada. Technical Translation 1102, 1963.]

Dyunin, A.K. and V.M. Kotlyakov. 1980. Redistribution of snow in the mountains under the effect of heavy snow-storms. Cold Reg. Sci. Technol., 3(4), 287-294.

Hunt, J.C.R. and A.H. Weber. 1979. A Langrangian statistical analysis of diffusion from a ground-level source in a turbulent boundary layer. Q. J. R. Meteorol. Soc., 105, 423-443.

Lee, L.W. Unpublished. Sublimation of snow in turbulent atmosphere. (Ph.D. thesis, University of Wyoming, 1975.)

Lyles, L. and B.E. Allison. 1976. Wind erosion: the protective role of simulated standing stubble. Trans. Am. Soc. Agric. Eng., 19, 61-64.

Mellor, M. and U. Radok. 1960. Some properties of drifting snow. In Antarctic Meteorology. Proceedings of the Symposium held in Melbourne, February 1959. New York, etc., Pergamon Press, 333-346.

Owen, P.R. 1964. Saltation of uniform grains in air. $J$. Fluid Mech., 20, 225-242.

Pomeroy, J.W. Unpublished. Wind transport of snow. (Ph.D. thesis, University of Saskatchewan, 1988.)

Pomeroy, J.W. and D.H. Male. 1986. Physical modelling of blowing snow for agricultural production. In Steppuhn, $\mathbf{H}$. and W. Nicholaichuk, eds. Snow Management for Agriculture. Proceedings of the Symposium. Saskatoon, Water Studies Institute, 73-108. (Great Plains Agricultural Council Publication 120.)

Schmidt, R.A. 1972. Sublimation of wind-transported snow - a model. Washington, DC, United States Department of Agriculture. Forest Service. (Research Paper RM-90.)

Schmidt, R.A. 1982. Vertical profiles of wind speed, snow concentration, and humidity in blowing snow. Boundary-Layer Meteorol., 23(2), 223-246.

Schmidt, R.A. 1986. Transport rate of drifting snow and the mean wind speed profile. Boundary-Layer Meteorol., 34(3), 213-241.

Tabler, R.D. 1975. Estimating the transport and evaporation of blowing snow. In Snow management on the great plains. Lincoln, NB, University of Nebraska, 85-105. (Great Plains Agricultural Council Publication 73.)

Tabler, R.D. 1980. Self-similarity of wind profiles in blowing snow allows outdoor modeling. J. Glaciol., 26(94), 421-434.

Tabler, R.D. and R.A. Schmidt. 1986. Snow erosion, transport and deposition in relation to agriculture. In Steppuhn, H. and W. Nicholaichuk, eds. Snow Management for Agriculture. Proceedings of the Symposium. Saskatoon, Water Studies Institute, 11-58. (Great Plains Agricultural Council Publication 120.)

Takeuchi, M. 1980. Vertical profile and horizontal increase of drift-snow transport. J. Glaciol., 26(94), 481-492. 